\title{
Modification of Wald and Savage Decision Criteria for Monopoly Market
}

\author{
Lilian Golban \\ golban.lilian@gmail.com \\ Academy of Economic Studies of Moldova, Republic of Moldova

\begin{abstract}
In this study are defined two decision-making models for analysis and the solution of manufacturing problems in the case of monopolistic markets, considering that consumer behavior is uncertain and demand cannot be derived beforehand, and with
\end{abstract} \\ knowledge of only some possible situations arise concerning demand.
}

Keywords: monopoly, decision criteria, function of regrets, states of nature, uncertainty.

JEL Code: C02, C61.

\section{Introduction}

Depending on the characteristics of the competition, an outlet market can be structured differently. At one extreme is placed the perfect competition, where more producers and consumers are present, and the activity is determined by very strict and clear rules, with no barriers to access or leaving the market. The monopoly market is characterized by the existence of only one producer and several consumers.

Monopolies are characterized by an absence of economic competition in the production of goods or services, as well as the absence of any other substitutable goods. Thus, only one producer has control of setting the price of the products offered to the market. A monopoly has the possibility to establish for what price a product will be sold and then, obviously, to decide what quantity should be marketed. For situations where the monopoly is acting under uncertainty (and this is given by the fact that the forecasts of the results are not accurate and may vary within a given range, the value of the risk cannot be quantified not at all and, regardless of the quantity or chose price, the same profit can no longer be guaranteed), it may be determined that market demand, as part of the training of the profit, it represents a random value, dependent on the fact that a monopolistic producer determines the quantum of the product or service sale [1].

Because uncertainty is the most commonly encountered condition in most economic systems, is actual to be analyzed how the monopoly will formulate its decisions, before is guaranteed a certain offer. At first sight, it may be considered that the monopolistic producer is likely to manufacture significant quantities of a product, as it is certain that consumers will be receptive and thus an extra profit will be ensured. But there are chances that this product will not enjoy such a high popularity and the manufacturer's expectations are far from the expected ones. If the manufacturer sees the situation from another point of view and prefers to be extremely careful, obviously, could decide to issue a smaller goods quantity on the market. Then, if the market will not be fully covered up, will result in a possible loss of profit from not providing sufficient goods quantities, corresponding to the actual market demand [2,3]. Therefore, it would be logical to consider new decision-making criteria for the design of decisions under uncertainty, by not being able to assess the probability of manifestation of nature's states.

\section{Materials and methods}

There are several strategies for managing the behavior of the monopoly producer. One of them involves maximizing the profit, by determining a certain production limit and marketing it at a price which is higher than its cost of production [3].

It is assumed a decision-making situation of production activity, in a monopoly market structure, as follows: 


$$
R(x, y, Y)=\sum_{j=1}^{n}\left[c_{j}\left(y_{j}\right) \cdot \min \left\{y_{j}, Y_{j}\right\}-p_{i} \cdot \max \left\{0, y_{j}-Y_{j}\right\}\right]-\sum_{i=1}^{m} q_{i} \cdot x_{i}
$$

in accordance with the following conditions:

$$
\begin{aligned}
& \sum_{j=1}^{n} a_{i j} y_{j} \leq b_{i}+x_{i}, i=\overline{l, m} \\
& y=\left(y_{1}, \ldots, y_{j}, \ldots, y_{n}\right) \in D_{y}=\left\{y \in E^{n}: \underline{y_{j}} \leq y_{j} \leq \overline{y_{j}}, j=\overline{l, n}\right\} \\
& Y=\left(Y_{1}, \ldots, Y_{j}, \ldots, Y_{n}\right) \in D_{Y}=\left\{Y \in E^{n}: \underline{Y_{j}} \leq Y_{j} \leq \overline{Y_{j}}, j=\overline{l, n}\right\} \\
& x=\left(x_{1}, \ldots, x_{i}, \ldots, x_{m}\right) \in D_{x}=\left\{x \in E^{m}: \underline{x_{i}} \leq x_{i} \leq \overline{x_{i}}, i=\overline{l, m}\right\}
\end{aligned}
$$

$R(x, y, Y)$ - producer's profit;

$y_{j}$ - amount of supply;

$Y_{j}$ - given amount of the good $j, j=\overline{l, n}$;

$x_{i}$ - amount of resource $i$, purchased at price $q_{i}, i=\overline{1, m}$,

$b_{i}$ - the available quantity of resources $i$.

It is considered that the price for the good $j, c_{j}\left(y_{j}\right)$ decreases linearly in the report with $y_{j}:$

$$
c_{j}\left(y_{j}\right)=\overline{c_{j}}-\left(\overline{c_{j}}-\underline{c_{j}}\right) \cdot\left(y_{j}-\underline{y_{j}}\right) /\left(\overline{y_{j}}-\underline{y_{j}}\right)
$$

Where: $c_{j}$ - price floor,

$\underline{y_{j}}$ - lowest demanded quantity,

$\overline{c_{j}}$ - price ceiling,

$\overline{y_{j}}$ - maximum demanded quantity.

Such the classical decision-making situations, two decision-making criteria are to be examined, namely:

- Pessimistic criterion or Wald criterion [4];

- Regret criterion or Savage's criterion [4].

\section{The "Wald" criterion or pessimistic criterion}

According to this criterion, for production models, the purpose of the decision maker is to identify that offer that would give him maximum profit for the most unfavorable conditions. The best option that determines the maximum profit, in accordance with Wald's criterion, will be identified according to the following rule:

$$
R_{W}(x, y)=\min _{Y} R(x, y, Y) \rightarrow \max _{(x, y)},
$$

where $Y$ - domain determined by the restriction (4).

The function $R_{W}(x, y)$ has the property to be concave relative to the set $(x, y)$ on the domain $D_{x} \times D_{y}$. 
Applying the generalized gradient method (Figure 1) [5,6,7], an algorithm is to be built that will solve the problem of the function maximization $R_{W}(x, y)$ on $D_{x} \times D_{y}$. Initially, are defined the following functions:

$$
\begin{gathered}
\Phi_{i}\left(x_{i}, y\right)=\sum_{j=1}^{n} a_{i j} y_{j}-b_{i}-x_{i}, i=\overline{l, m} ; \\
\Phi(x, y)=\max \left\{\Phi_{1}\left(x_{1}, y\right), \ldots, \Phi_{m}\left(x_{m}, y\right)\right\}
\end{gathered}
$$

For each $k=0,1, \ldots$, an iterative calculation process is launched, which consists in building two series of vectors $\left\{y^{k}\right\}$ and $\left\{x^{k}\right\}$ according to the rules:

$$
\begin{gathered}
\text { if } \Phi\left(x^{k}, y^{k}\right) \leq \delta_{k} \text {, then: }\left\{\begin{array}{l}
y^{k+1}=P_{D_{y}}\left(y^{k}+h_{k} \cdot g_{y}^{k}\right), \text { where } g_{y}^{k}=\operatorname{grad} R_{y}\left(x^{k}, y^{k}, Y^{k}\right), \\
x^{k+1}=P_{D_{x}}\left(x^{k}+h_{k} \cdot g_{x}^{k}\right), \text { where } g_{x}^{k}=\operatorname{grad} R_{x}\left(x^{k}, y^{k}, Y^{k}\right) .
\end{array}\right\}, \\
\text { if } \Phi\left(x^{k}, y^{k}\right)>\delta_{k} \text {, then: }\left\{\begin{array}{l}
y^{k+1}=P_{D_{y}}\left(y^{k}-h_{k} \cdot g_{y}^{k}\right), \text { where } g_{y}^{k}=\operatorname{grad} \Phi_{y}\left(x^{k}, y^{k}\right), \\
x^{k+1}=P_{D_{x}}\left(x^{k}-h_{k} \cdot g_{x}^{k}\right), \text { where } g_{x}^{k}=\operatorname{grad} \Phi_{x}\left(x^{k}, y^{k}\right) .
\end{array}\right\}
\end{gathered}
$$

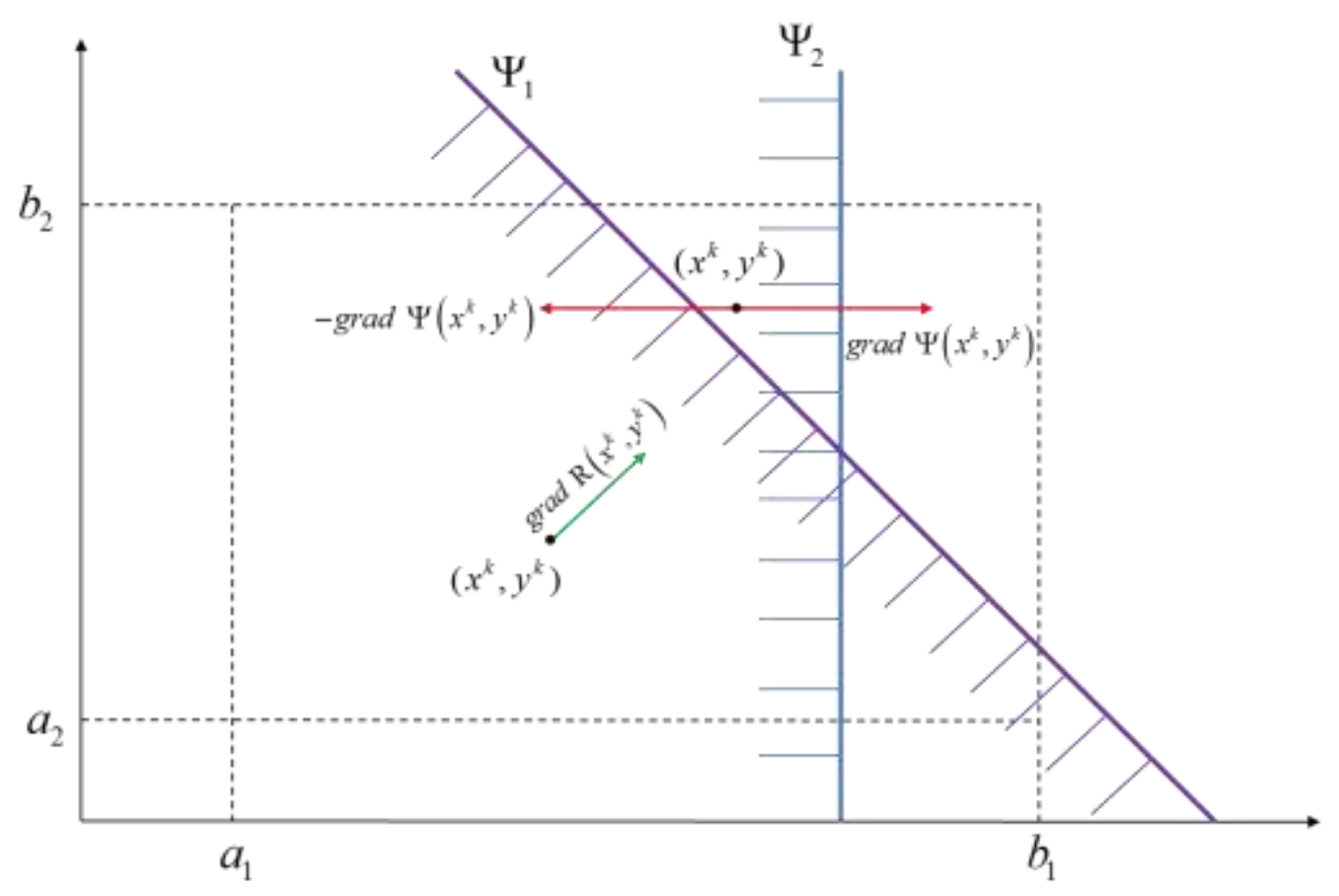

Figure 1. General view of graphical representation for estimations of "generalized gradients" for two states of nature

In that case, $Y^{0}$ - is an arbitrate element from $D_{Y}$ (f or example, randomly generated).

For each $k \geq 1$, the element $Y^{k}$ the element is determined as follows:

$$
Y^{k}=\left\{\begin{array}{l}
Y^{k-1}, \text { if } R\left(x^{k}, y^{k}, Y^{k-1}\right) \leq R\left(x^{k}, y^{k}, Y^{k}\right) \\
Y^{k}, \text { if } R\left(x^{k}, y^{k}, Y^{k-1}\right)>R\left(x^{k}, y^{k}, Y^{k}\right)
\end{array}\right\} .
$$

Here $Y^{k}$ is an element from $D_{Y}$ randomly generated at iteration $k$ according to the distribution law $p(d Y)$ (which, for example, it may be uniform distribution on the $D_{Y}$ domain). 
For illustration and for an overall perspective, it is assumed the set of "states of nature" includes two elements. According to this model, the optimal decision (Figure 2) determines the maximal utility as follows:

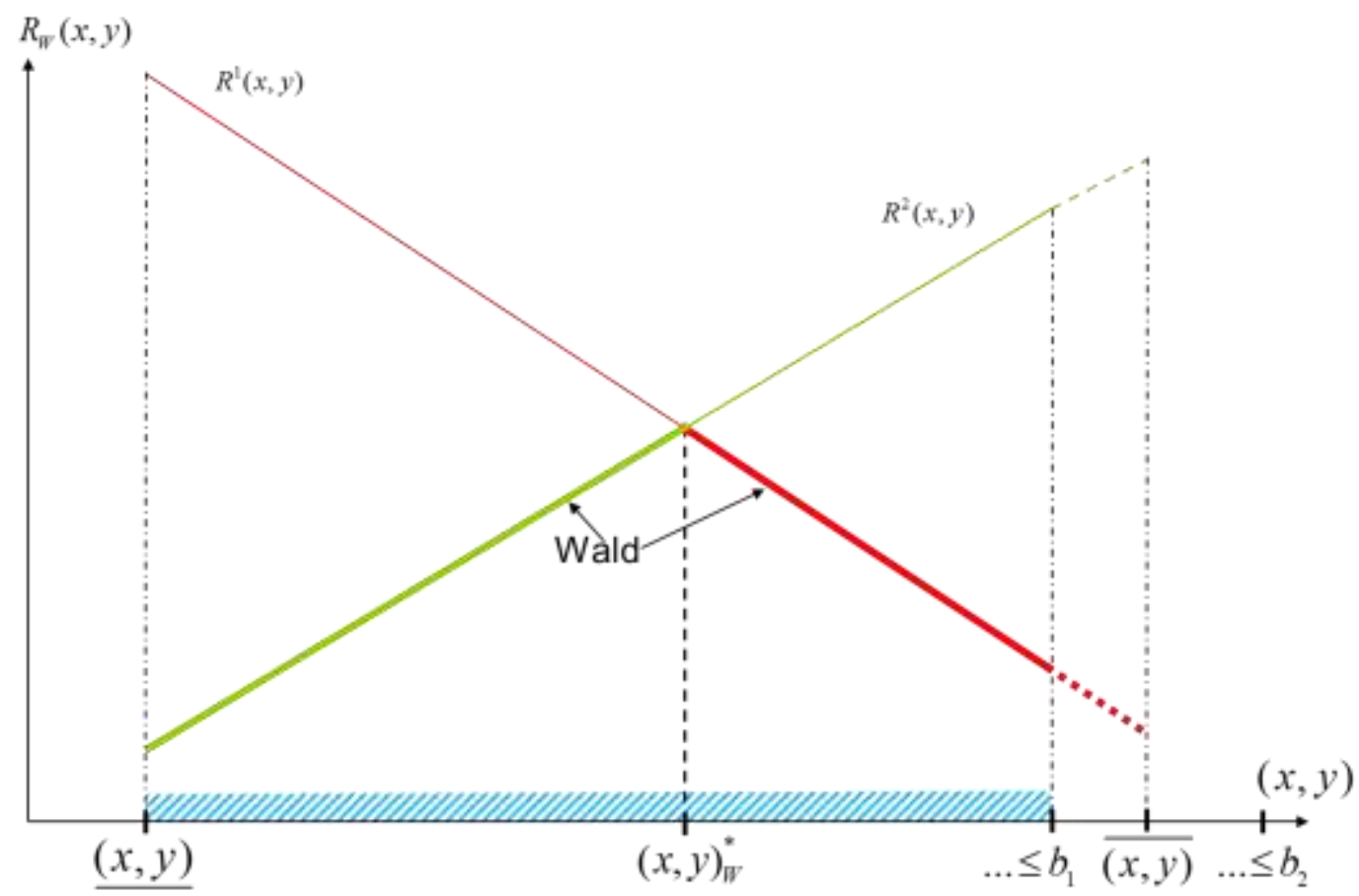

Figure 2. General view of graphical interpretation of Wald function for two states of nature

\section{The "Savage" criterion or regret criterion}

Conform to Savage $[8,9]$, the regret is the decider's loss by the failure to select the best alternative in relation to the achievement of a given nature's state. The goal to minimize the objective function (known as Savage's function) is the following:

$$
R_{S}(x, y)=\max _{Y}\left(\max _{(x, y)} R(x, y, Y)-R(x, y, Y)\right) \rightarrow \min _{(x, y)}
$$

The function $R_{S}(x, y)$ The function is convex in relation to set $(x, y)$ on $D_{x} \times D_{y}$.

Thus, in Savage's approach, it is considered the following algorithm for solving the monopoly market model:

1) In conformity with the uniform distribution law on the domain $D_{Y}$, a set of components is generated randomly (these are independent random generated vectors) $Y^{l}, \ldots, Y^{l}, \ldots, Y^{L}$, being considered, on the whole, as a sample of the crowd $D_{Y}$.

2) Are considered $L$ optimization problems, known as "internal problems"

$$
R^{l}(x, y)=R\left(x, y, Y^{l}\right) \rightarrow \max _{(x, y)}, l=1,2, \ldots, L
$$

respecting the condition: $\Phi(x, y) \leq 0 ;(x, y) \in D_{x} \times D_{y}$

Whether $\left(x^{*}, y^{*}\right)^{l}$ is the optimal solution of the problem $l(l=\overline{l, L})$ and $R^{* l}=\max _{(x, y)} R^{l}(x, y)$

3) It is considered the following problem (known as "external problems"), which, as a matter of fact, it is a stochastic approximation of the Savage criterion.

$$
R_{S}(x, y)=\max _{l \leq l \leq L}\left[R^{* l}-R^{l}(x, y)\right] \rightarrow \min _{(x, y)}
$$

4) Are set up $L+1$ sequence of numbers as follows: 
$\left\{x^{k l}, y^{k l}\right\}, l=\overline{l, L},\left\{x^{k}, y^{k}\right\}, k=0,1,2, \ldots$, where $\left(x^{0 l}, y^{o l}\right)$ and $\left(x^{0}, y^{o}\right)$ they are a priori determined from the crowd $D_{x} \times D_{y}$. The elements $\left(x^{0 l}, y^{o l}\right), l=\overline{l, L},\left(x^{0}, y^{o}\right)$ they'll name points of start for the $L+1$ problems.

5) Two numeric strings are going to be determined, $h_{k}$ and $\delta_{k}$ :

$$
h_{k}>0, h_{k} \rightarrow 0, \delta_{k}>0, \delta_{k} \rightarrow 0, \sum_{k=0}^{\infty} h_{k} \delta_{k}=\infty, h_{k} / \delta_{k} \rightarrow 0 .
$$

Note: the conditions for determining of $h_{k}$ and $\delta_{k}$ have to be applied also for Wald's criterion.

6) Is considered that already are known the points $\left\{x^{k l}, y^{k l}\right\}, l=\overline{l, L}$ and $\left\{x^{k}, y^{k}\right\}$. The successive elements $\left\{x^{(k+1) l}, y^{(k+1) l}\right\}, l=\overline{l, L},\left\{x^{k+1}, y^{k+1}\right\}$ are calculated as follows:

$$
\begin{aligned}
& \text { if } \Phi\left(x^{k l}, y^{k l}\right) \leq \delta_{k} \text {, then: }\left\{\begin{array}{l}
x^{(k+1) l}=P_{D_{x}}\left(x^{k l}+h_{k} \cdot g_{x}^{k l}\right), g_{x}^{k l}=\operatorname{grad}_{x} R^{l}\left(x^{k l}, y^{k l}\right), \\
y^{(k+1) l}=P_{D_{y}}\left(y^{k l}+h_{k} \cdot g_{y}^{k l}\right), g_{y}^{k l}=\operatorname{grad}_{y} R^{l}\left(x^{k l}, y^{k l}\right) .
\end{array}\right\}, \\
& \text { if } \Phi\left(x^{k l}, y^{k l}\right)>\delta_{k} \text {, then: }\left\{\begin{array}{l}
x^{(k+1) l}=P_{D_{x}}\left(x^{k l}-h_{k} \cdot g_{x}^{k l}\right), g_{x}^{k l}=\operatorname{grad}_{x} \Phi\left(x^{k l}, y^{k l}\right), \\
y^{(k+1) l}=P_{D_{y}}\left(y^{k l}-h_{k} \cdot g_{y}^{k l}\right), g_{y}^{k l}=\operatorname{grad}_{y} \Phi\left(x^{k l}, y^{k l}\right) .
\end{array}\right\}, \\
& \text { if } \Phi\left(x^{k}, y^{k}\right) \leq \delta_{k} \text {, then: }\left\{\begin{array}{l}
x^{k+1}=P_{D_{x}}\left(x^{k}-h_{k} \cdot g_{x}^{k}\right), g_{x}^{k}=\operatorname{grad}_{x} R_{S}^{k}\left(x^{k}, y^{k}\right), \\
y^{k+1}=P_{D_{y}}\left(y^{k}-h_{k} \cdot g_{y}^{k}\right), g_{y}^{k}=\operatorname{grad}_{y} R_{S}^{k}\left(x^{k}, y^{k}\right) .
\end{array}\right\}, \\
& \text { if } \Phi\left(x^{k}, y^{k}\right)>\delta_{k} \text {, then: }\left\{\begin{array}{l}
x^{k+1}=P_{D_{x}}\left(x^{k}-h_{k} \cdot g_{x}^{k}\right), g_{x}^{k}=\operatorname{grad}_{x} \Phi\left(x^{k}, y^{k}\right), \\
y^{k+1}=P_{D_{y}}\left(y^{k}-h_{k} \cdot g_{y}^{k}\right), g_{y}^{k}=\operatorname{grad}_{y} \Phi\left(x^{k}, y^{k}\right) .
\end{array}\right\} .
\end{aligned}
$$

Here:

$$
R_{S}^{k}\left(x^{k}, y^{k}\right)=\max _{l \leq l \leq L}\left[R^{l}\left(x^{k l}, y^{k l}\right)-R^{l}\left(x^{k}, y^{k}\right)\right] \rightarrow \min _{(x, y)}
$$

Depending on the chosen criterion, the optimal solution will be different for both models [10]. In Figure 3[11] is presented a graphic interpretation, from a general view, how the decision will be taken for case when there are analyzed only two states of nature: 


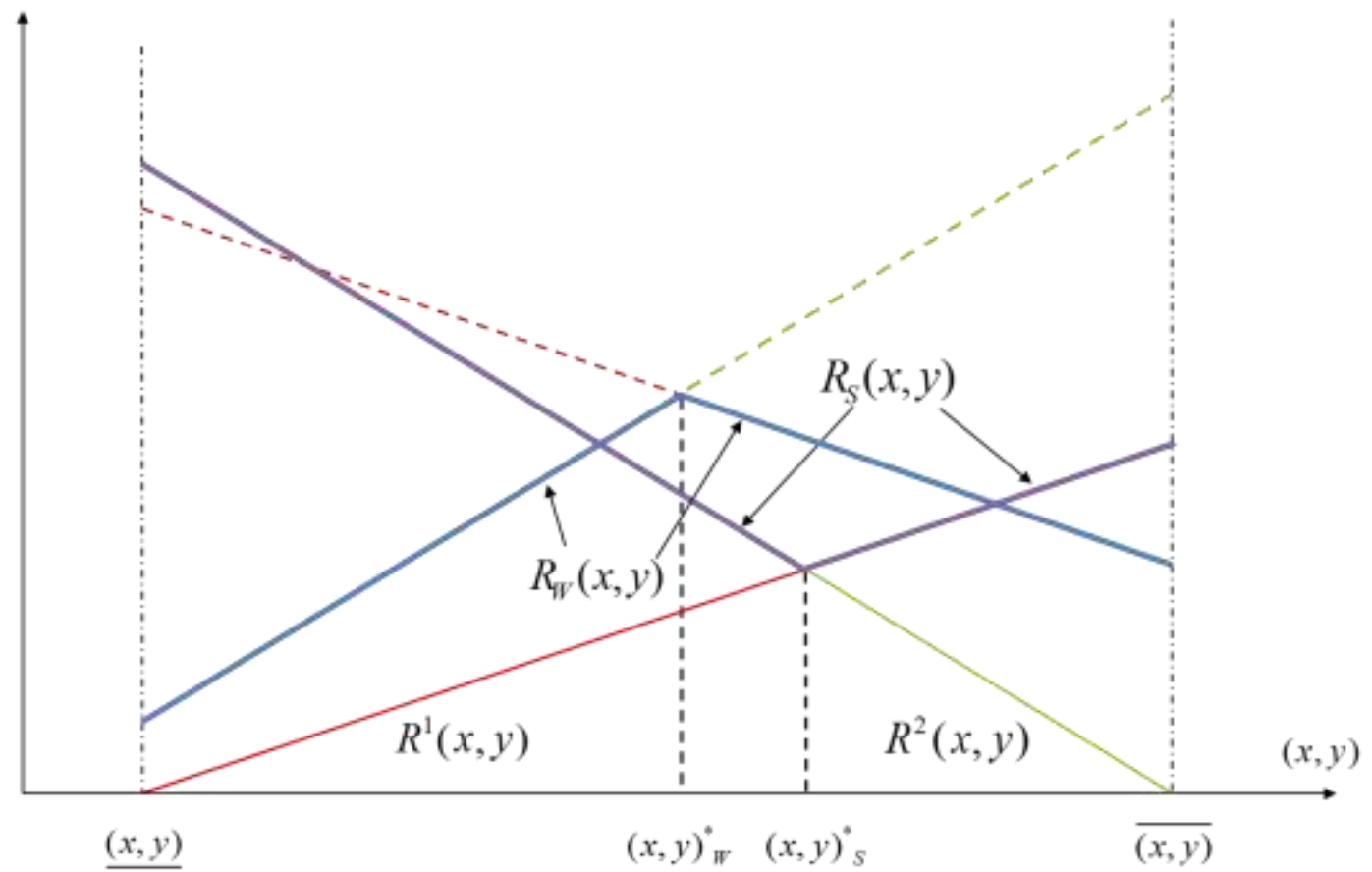

Figure 3. Graphical interpretation of Wald and Savage functions and their optimal solutions

\section{Conclusions}

Under uncertainty, the decider should choose one of the existing alternatives having only some information on their profitability. In this paper are describe the theoretical aspects of the applicability of Wald and Savage criteria, adjusted to the goal of maximizing the profit of the monopoly with the direct use of the generalized gradient method. The described algorithms are iterative; their special feature consists of "getting closer" to the proximity of the optimal solution, with some approximation, acceptable for all the nature states included in the mathematical model. The algorithm described for the pessimistic criterion, as its name says, is characterized by providing a solution which will guarantee the decider a certain profit, despite the realization of even the most unfavorable state of nature. This approach will help the producer to ensure that for any market configuration, even close to pure uncertainty, will not result in losses of profitability. Obviously, for situations where the monopoly is tending to achieve maximum profit, with a minimal regret, it is advisable to apply the SAVAGE criterion. It differs from the pessimistic regret because the purpose of the problem is fixed to minimize the regret, which indirectly implies the building of the best offer that will maximize profit for all the states of nature. In parallel with the solving of the global problem, at every iteration, the so-called "internal problems" are solved as well, which describes, in particular, the states of nature. This particularity of the algorithm, grace to its integration with the method of the generalized gradient, allows being built a new solution, for every iteration, which is an admissible solution but has the trend to approach the very close vicinity of the existing optimal solution. In the case of acting according to SAVAGE criterion, the velocity of achieving the optimal solution depends on the maximum number of iteration the algorithm is going to be executed for, but not less important, the automatic step change scheme $h_{k}$ and the tolerance threshold $\delta_{k}$. The tolerance threshold represents the approximation which the decedent may neglect, but it has the role to stop the algorithm at the moment when it does not exceed a certain predefined value. This part of the algorithm helps to reduce the time for a response obtaining and to diminish overstrain of the sub-system. The desire to achieve a solution that is much too accurate can no longer be current at the time it will be generated by algorithm. 


\section{References}

1. E. Zabel, "Monopoly and Uncertainty". The Review of Economic Studies Vol. 37, No. 2 (Apr., 1970), pp. 205-219;

2. James D. Dana, Jr., "Monopoly Price Dispersion under Demand Uncertainty". International Economic Review Vol. 42, No. 3 (Aug., 2001), pp. 649-670;

3. Andrei Gametchi, Dumitru Solomon, Modelarea matematică a proceselor economice. Editura Evrica, Chişinău-1998, pp. 164-210, 222-223, 248-253;

4. Hamdy A. Taba, Operations research an introduction, 3rd edition. London 1982;

5. Шор Н. 3., Методы минимизачии недифферениируемвгх функиий и их приложения. Киев, „Наукова Аумка”, 1979;

6. Anatol Godonoagă, Anatolie Baractari, Modele economice nediferențiabile. Aspecte deciz̨ionale. Editura ASEM, Chișinăn - 2011, pp. 52-100;

7. Lilian Golban, Linear models with uncertainty factors and some aspects of decision making, The 16th International Conference on Informatics in Economy (IE 2017), Bucharest 04-07 May 2017;

8. Savage L. J., The theory of statistical decision. J. Amer. Statist. Assoc., 1951, vol. 46, no. 1, pp. 55-67;

9. Ionescu Gh., Cazan E., Negrusa A., Modelarea şi optimizarea deciziilor manageriale. Cluj-Napoca, Editura Dacia, 1999;

10. Lilian Golban, Anatol Godonoagă, "Aspecte decizionale privind modelarea incertitudinii în diverse activități economice", The 42nd American Romanian Academy of Arts and Science Congress (ARA), pp. 51, 23-26 mai 2018, University Babeș-Bolyai, Cluj-Napoca, România.

11. Годонога А. Ф., Голбан А. А., Чумаков Б. М., "Некоторые модели принятия решений в условиях неопределености", Теория оптимальньх решений, 2018, Nr. 17, Начиональная академия наук Украины, Институт кибернетики, имени В. М. Глушкова, Киев 2018, pag. 130-137, ISSN 26165619. 